\title{
A Percepção dos Empresários Sobre a Consultoria em Gestão de Pessoas na Região do Cariri
}

\author{
Márcia Marta de Carvalho ${ }^{1}$; Larissa Vasconcelos Rodrigues ${ }^{2}$
}

\begin{abstract}
Resumo: Percebe-se que consultoria é uma área bastante desafiadora nas organizações, pois tem papel de analisar as organizações com em suas esferas positivas e negativas, buscando a otimização de resultados. Assim, o objetivo dessa pesquisa é analisar a opinião dos empresários da Região do Cariri sobre a consultoria em Gestão de Pessoas, tendo como tipo de pesquisa quanti-qualitativa, por meio de dados coletados através de um questionário aplicado a 101 empresários da Região do Cariri, buscando verificar a opinião dos mesmos sobre consultoria em Gestão de Pessoas. Ao longo da pesquisa, destacam-se alguns conceitos de gestão de pessoas e consultoria empresarial relacionada ao tema apresentado. A pesquisa busca despertar uma atenção a consultoria em gestão de pessoas, sendo importantes para empresas na Região do Cariri analisar este ramo em busca de aumentar resultados nas suas organizações.
\end{abstract}

Palavras Chave: Consultoria. Gestão de Pessoas. Planejamento Estratégico.

\section{Entrepreneurs' Perception of the Management People Consulting in the Region of Cariri}

\begin{abstract}
It is perceived that consulting is a very challenging area in organizations, as it has the role of analyzing organizations with their positive and negative spheres, seeking the optimization of results. Thus, the objective of this research is to analyze the opinion of the entrepreneurs of the Cariri Region on the consulting in People Management, having as quantitative-qualitative type of research, through data collected through a questionnaire applied to 101 entrepreneurs of the Region of Cariri, seeking to verify their opinion on consulting in People Management. Throughout the research, we highlight some concepts of people management and business consulting related to the theme presented. The research seeks to attract attention to people management consulting, and it is important for companies in the Cariri Region to analyze this branch in order to increase results in their organizations.
\end{abstract}

Keywords: Consulting. People management. Strategic planning.

\section{Introdução}

O investimento em pessoas torna-se altamente lucrativo, pois a empresa apresenta muito mais resultados significativos através dos seus colaboradores, quando há uma boa gestão.

A pesquisa tem como base, a consultoria em gestão de pessoas, que busca maximizar resultados externos na organização através da satisfação dos seus funcionários, sobretudo motivando-os para

\footnotetext{
${ }^{1}$ Graduanda do curso de Administração do Centro Universitário Doutor Leão Sampaio/Unileão.

Contato: marciamarta2017@gmail.com;

${ }^{2}$ Professora Orientadora do Centro Universitário Doutor Leão Sampaio/Unileão, Especialista. 
desenvolver um trabalho diferenciado, com o objetivo de criar oportunidades para crescer dentro da empresa.

Desse modo, para desenvolver uma boa gestão a consultoria é uma ferramenta essencial para auxiliar em determinados problemas empresa-cliente, mostrando resultados significativos e sendo um grande diferencial para as pessoas, sobretudo, procurando solucionar problemas mais rápidos de maneira significativa para seu cliente.

A Gestão de Pessoas é um desafio diário para os líderes da organização. Visto a necessidade de lidar com as novas realidades, tecnologias, satisfação, insatisfação da gestão de pessoas entre outros. A atuação de um profissional é de fundamental importância para maximizar os resultados e elevar o nível de produtividade.

Visto que o consultor está atento as mudanças requeridas pelo mercado de trabalho, e possui Know how que é um termo utilizado para designar as vantagens competitivas de uma organização. Sendo assim a consultoria é uma ferramenta que a Gestão de Pessoas utiliza para uma análise do ambiente organizacional com objetivo de tomar decisão para pôr em práticas nas organizações, pois a consultoria são estratégias que os gestores adotam para visualizar caminhos eficazes, pois qualquer empresa busca maximizar seus resultados para aumentar sua produtividade e a consultoria é uma ferramenta chave para esse processo.

Sendo assim torna se importante analisar como os empresários percebem a consultoria em gestão de pessoas. Desse modo surge o questionamento: quais são as principais opiniões que os empresários da Região do Cariri possuem sobre a consultoria em Gestão de Pessoas?

Pode-se inferir que os empresários não conhecem a consultoria em gestão de pessoas e com isso há pouco investimento no desenvolvimento das pessoas que trabalha em suas organizações.

O presente artigo tem como objetivo analisar a opinião dos empresários da Região do Cariri sobre a consultoria em Gestão de Pessoas, tendo como tipo de pesquisa quanti-qualitativa, por meio de dados coletados através de um questionário aplicado a 101 empresários da Região do Cariri, buscando verificar a opinião dos mesmos sobre consultoria em Gestão de Pessoas, assim, foi possível analisar se estes a analise destes conhecem este serviço, já utilizaram ou pretendem utilizar nas suas organizações.

Torna-se necessário mostrar que o consultor atua em um papel importante para a organização, procurando sempre estabelecer metas e prazos para obter resultados crescentes e desafiadores, pois surge com uma visão ampla para melhorar o ambiente interno e externo, onde o consultor possui um conhecimento no comportamento organizacional tanto no ambiente interno (cultura, clima etc.) quanto externo (econômico, mercado e cenário). Nessa perspectiva, torna-se fundamental esse conhecimento na sua especialização acadêmica.

Percebe-se a consultoria como uma área bastante desafiadora, pois para atuar na área deve-se analisar o perfil e verificar a adequação necessária a esta função. Enquanto pesquisadora interessada

428 Id on Line Rev. Mult. Psic. V.12, N. 42, Supl. 1, p. 427-446, 2018 - ISSN 1981-1179 Edição eletrônica em http://idonline.emnuvens.com.br/id 
nessa atuação se faz necessário identificar as habilidades e competências. Em uma análise social, o objetivo é que a consultoria tenha uma proposta de melhoria, proporcionando aos gestores aumentar sua eficiência e eficácia.

Para profissionais de consultoria em gestão de pessoas este artigo servirá para ampliar suas discussões e opiniões sobre a consultoria em gestão de pessoas, sobretudo, proporcionando novas configurações sobre sua atuação nas organizações.

Assim, o profissional em consultoria em Gestão de Pessoas pode contribuir para melhoramento da organização em uma boa gestão que gere resultados positivos, desenvolvendo pesquisas qualitativas através de entrevistas, com método adequado e aprofundado para obter resultados.

\section{Referencial Teórico}

\section{Gestão de Pessoas}

As pessoas constituem o principal ponto na organização. Com isso há uma importância de destacar o papel de seus funcionários, para que desenvolva uma organização com um bom resultado. A gestão de pessoas permite com que eleve o seu desempenho dentro da organização.

Para Gil (2001, p.21 apud CRUZ, SOUZA, OLIVEIRA, 2001) a gestão de pessoas "é a função gerencial que visa a cooperação das pessoas que atuam nas organizações para alcance dos objetivos tanto organizacionais quanto individuais".

Para obter um bom resultado nas empresas é essencial que seus colaboradores estejam satisfeitos com seu ambiente de trabalho, todo esse processo produtivo possui uma ligação com seus colaboradores para desenvolver um bom desempenho, pois as empresas são constituídas de pessoas.

Conforme Gil (2001 apud CRUZ, SOUZA, OLIVEIRA, 2001) surge a administração de recursos humanos na década de 60 , destinadas a tratar de assuntos relacionados aos seus colaboradores da empresa. Com isso surgem vários desafios organizacionais, sendo as mudanças no mundo de mercado com isso alguns gestores temem a essa mudança futura.

A gestão é vista como parte essencial para decisões nos recursos humanos, visando maximização dos benefícios, a administração de recursos humanos tem como papel importante torna se os resultados eficaz e eficiente na organização.

Para Chiavenato (2014) a gestão de pessoas é uma área muito sensível a mentalidade e a cultura corporativa que predomina na organização, pois depende de vários aspectos. As pessoas são a base para uma organização que geram conhecimentos, habilidades, competências e proporciona decisões que geram um objetivo.

429 Id on Line Rev. Mult. Psic. V.12, N. 42, Supl. 1, p. 427-446, 2018 - ISSN 1981-1179 Edição eletrônica em http://idonline.emnuvens.com.br/id 
Com isso, a organização fica atenta para seus colaboradores, pois os resultados são percebidos quando mantem os processos de aperfeiçoar, pois permite que seus colaboradores sejam eficientes para alcançar seus objetivos organizacionais (CHIAVENATO, 2014) visa a colaboração de todos para que possa atingir objetivos organizacionais e satisfazer as necessidades de todos seus colaboradores assim desenvolve uma boa gestão.

Através dos processos de gestão de pessoas organização busca desenvolver resultados para aperfeiçoar seu desempenho organizacional; esse processo facilita as atividades na organização, o acompanhamento de todo desempenho organizacional (aplicar), conter recompensas para seus colaboradores satisfazendo suas necessidades individuais (recompensar), o profissional desenvolve seu crescimento na organização (desenvolver), o processo das inclusões de pessoas favorecendo suas condições ambientais e psicológicas para atividade das pessoas (manter pessoas), e acompanhamento de todo processo na organização (monitorar) (CHIAVENATO, 2014).

Segundo Ribeiro (2006, p. 01) "a área de recursos humanos tem como objetivo principal administrar as relações da organização com as pessoas que a compõe".

Figura 1: Recursos Humanos

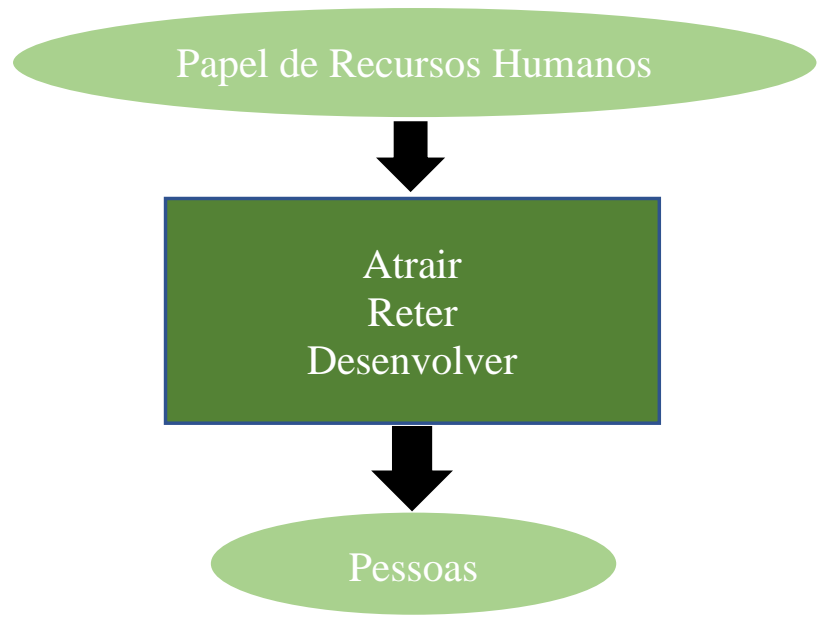

Fonte: Ribeiro (2006).

Todos esses processos são de suma importância na gestão de pessoas, pois permite que inicie uma consultoria onde irá analisar cada processo para desenvolver nas empresas de acordo com seu conhecimento. 


\section{Consultoria Empresarial}

A evolução do contexto de consultoria passou a ser um referencial encontrado nas organizações em respostas a sua escolha nos processos da administração com contribuição na gestão de pessoas. É um termo utilizado por pessoas para uma análise no ambiente organizacional, com objetivo de oferecer opções de mudanças para tomada de decisão certa, nas necessidades das organizações, pois os desafios surgem aumentando e afetando de diversos ângulos nas empresas. Outro fator que surge é entender o que é a consultoria, assim menciona-se abaixo alguns conceitos.

Consultoria é o conjunto estruturado de atividades sequencias ocorridos na empresa que auxilia seus profissionais para o controle de uma situação (OLIVEIRA, 2015) dada determinada situação o consultor tem como foco principal, resolve os problemas ocorridos insatisfatoriamente com seus colaboradores.

O consultor é um facilitador dos processos de mudanças que tem uma grande importância, mediante seus dirigentes, líderes, e profissionais de gestão de pessoas que são companheiros nesses desafios. (LEITE et al., 2009) O consultor identificar as mudanças necessárias para diminuir riscos e maximizar resultados, mesmo em meios a algumas alterações no mercado. Diante desse fato, o consultor contribui para resultados na gestão de pessoas nas organizações quando realiza de forma segura e estratégica para alcançar resultados significativos através da contribuição da gestão de pessoas, ou seja, através das pessoas a empresa alcança resultados positivos na organização.

Segundo Oliveira (2015, p.04), consultoria é o "Processo interativo de um agente de mudanças externo á empresa, que assume a responsabilidade de auxiliar seus executivos e profissionais nas tomadas de decisão, não tendo o controle direto da situação".

Com definição mais delineada nesse contexto de consultoria, o processo interativo é todo conjunto de atividades sequenciadas que busca atender as necessidades dos clientes. E interação significa que uma ação recebe e dá algo pessoas, portanto o processo interativo depende de um ponto comum a outro são interligados entre si. E o agente de mudanças é o profissional que promove comportamentos que produza interação de diversos fatores no ambiente organizacional da empresa tendo como a responsabilidade de auxiliar quando não se tem controle sobre qualquer situação. (CROCCO e GUTTMANN, 2005).

Conforme Weis (2012), o consultor é o que traz conhecimento, novas habilidades e outras especificações para que cliente mude seu comportamento na sua empresa e que receba uma remuneração sobre seu trabalho realizado perante o caso solucionado, e define ainda mais, o consultor é o que ajuda a melhora seu cliente.

Mencionando-se os contextos sobre consultoria, ressalta-se que chega à seguinte conclusão sobre a sua definição:

431 Id on Line Rev. Mult. Psic. V.12, N. 42, Supl. 1, p. 427-446, 2018 - ISSN 1981-1179 Edição eletrônica em http://idonline.emnuvens.com.br/id 
Consultoria é um processo interativo executado por uma ou mais pessoas independentes e externas ao problema em analise com objetivo de fornecer ao executivo da empresa cliente um ou mais conjuntos de opções de mudanças que proporcione a tomada de decisões mais adequada ao atendimento das necessidades da organização (OLIVEIRA, 2015, p.21).

Onde a empresa busca maximização dos resultados, aumentando o índice de produtividade para desenvolver resultados significativos na organização, à consultoria empresarial desenvolve um recurso necessário para administradores para resolução de seus trabalhos. Assim, a consultoria para profissionais possui um elevado conhecimento para alcance de bons resultados, desta forma este profissional deve produzir bastante conhecimento para que esse consultor empresarial analise as oportunidades de melhorias para a organização. Ao revê todos os conceitos relacionados ao consultor terá a relação como planejamento estratégico que torna se um fato importante para consultoria está intimamente ligado a um bom consultor atuar com bom planejamento estratégico resolvendo alguns problemas ocorridos na empresa.

O consultor tem um papel importante nas organizações, pois destacamos como funções admiráveis para coordená-la. Tem um papel facilitar toda a decisão tomada diante sua empresa, com isso esse profissional procura assimilar com gestor em pessoas. O consultor acima de tudo é focado em suas metas e prazos para obter resultados qualificados buscando enfrentar seus desafios organizacionais trazendo soluções perante suas ações cotidianas.

\section{Planejamento Estratégico}

O planejamento estratégico é uma ferramenta essencial. Tornou-se comum nas empresas, pois tem como função transformar objetivos e metas por avaliar causas internas e externas nas empresas. A empresa estabelece um plano para onde pretende chegar e qual plano será colocado para que tenha sucesso. As organizações precisam planejar suas ações para que inicie seus trabalhos em um ambiente de concorrência. Para melhor entendimento segue alguns conceitos chaves sobre planejamento estratégico;

Segundo Fidelis (2014, p.31) "planejar significa estruturar com base em uma ideia todas as possibilidades e oportunidades de desenvolvimento do negocio, permitindo a analise dos objetivos futuros com foco na eficiência, eficácia e efetividade de ações e pessoas para alcance de uma posição desejada”. Isso é uma forma de enxergamos o futuro de uma maneira que possa ampliar e avaliar todas as possibilidades de oportunidades que gere resultados nas suas decisões tomadas.

432 Id on Line Rev. Mult. Psic. V.12, N. 42, Supl. 1, p. 427-446, 2018 - ISSN 1981-1179 Edição eletrônica em http://idonline.emnuvens.com.br/id 
"Planejamento estratégico são como as estratégias organizacionais esta inserida em sua missão no lugar que atua" (CHIAVENATO, SAPIRO, 2003). "O processo estratégico é também soluções e composições para avaliar as estratégias atuais e futuras" (BULGACOV et al., 2007).

Segundo Fidelis (2014) o planejamento estratégico subdivide em três níveis: operacional, tático, estratégicos.

$\checkmark \quad$ O nível operacional: tem como objetivo as operações de trabalhos que esta relacionada às ações de curto prazo.

$\checkmark$ O nível tático: recursos relacionados a curto e médio prazo relacionados ao ambiente interno que afetam a parte da empresa.

$\checkmark \quad$ Nível estratégico: realiza estratégia com intuito de obter resultados ao longo prazo, e reque muito planejamento de analise internas e externas.

O planejamento estratégico corresponde a suas decisões tomadas onde são definidas acimas, e estimula os impactos em todos os níveis da empresa (interna e externa).

Conforme Oliveira (2018) mostra outras definições sobre planejamento estratégico;

Planejamento estratégico: é o processo que ajuda na área administrativa e atua com estratégias estabelecidas pelas empresas, otimizando os fatores internos externos.

Planejamento tático: atua em parte da empresa visando determinada área para melhores resultados. Planejamento operacional: é o foco através de documentos escritos, é a parte da implementação.

Com isso trabalha para aumentar os resultados diminuindo os riscos utilizando princípios como eficiência, eficácia e efetividade são aspectos para ação de resultados em uma boa gestão. "Eficiência baseados em distinguir os problemas, fazer as coisas corretas, e ter seus dever cumprido. Eficácia maximizar os resultados, fazer as coisas certas, e produzir mais. Efetividade apresenta resultados significativos." (CHIAVENATO e SAPIRO, 2003).

Sendo assim o planejamento estratégico desenvolve alguns instrumentos para melhoria dos seus processos que contem estratégias que ajuda a desenvolver o trabalho na organização.

São eles:

\section{- Matriz De Crescimento E Participação No Mercado}

Desenvolvida em uma empresa de consultoria e gestão, surge para delimitar questões inspiradas na área financeira. 
Figura 2 - Matriz de crescimento

\begin{tabular}{|l|l|}
\hline Estrelas & Em questionamento \\
\hline Vaca leiteira & Abacaxi \\
\hline
\end{tabular}

\section{ALTO}

BAIXO

Vaca leiteira: na figura acima, esse quadrante mostra a alta participação no mercado e de baixo crescimento. Estrela: sãos os produtos com alta participação em um setor de alto crescimento.

Questionamento: é o produto com participação baixa no mercado com alto crescimento.

Abacaxi: produtos com baixa participação em um mercado com baixo

Fonte: Adaptado de Tavares (2010)

A figura acima mostra que quem apresenta um nível de lucro maior, tem que ter uma alta participação no mercado para mostrar a competitividade dessa a empresa (TAVARES, 2010).

\section{- Análise SWOT}

Segundo Tavares (2010) análise swot "o conceito de SWOT - forças, fraquezas, oportunidades, ameaças, começou a populariza, a partir e uma conferência sobre políticas de negócios”.

Figura 3 - Relação entre oportunidades forças, ameaças, e fraquezas.

\begin{tabular}{|l|l|}
\hline Oportunidades & Fraquezas \\
\hline
\end{tabular}

Fonte: Adaptado de Tavares (2010) 
Acima nos mostra uma das análises desenvolvidas para analisar sua competitividade empresarial, nas forças e fraquezas, e está relacionada com seus concorrentes. A empresa utiliza essas para saber o que está fazendo melhor em mercado competidos.

Para Tavares (2010, p.265) "a analise SWOT é empreendida para acrescentar valor a esse consumidor", ou seja, visto que a organização deve ter um foco principal para consumidor.

Nas oportunidades e ameaças, são contidas fora da organização, é uma forma de tornar a empresa mais competitiva e alavancar suas forças agindo de forma que não intervenha no ambiente trabalho.

\section{- Modelo Porter}

As cincos forças é uma ferramenta que auxilia na definição da estratégia da organização.

"Os enfoques de Porter, são questões essências que segundo ele, são fatores determinantes para estratégias competitiva de uma organização" (BETHLEM 2002). Portanto, as forças de Porter utilizam estratégias que busque a melhor forma para a empresa, determinando formas mais lucrativas e consentindo um bom posicionamento da empresa dentro do negócio. As cincos forças se resumem em: a) A ameaça de novos concorrentes; b) A ameaça de produtos substitutos; c) O poder de barganha dos compradores; d) O poder de barganha de fornecedores; e e) A rivalidade entre os competidores existentes

Figura 4 - Forças que regem a concorrência do setor

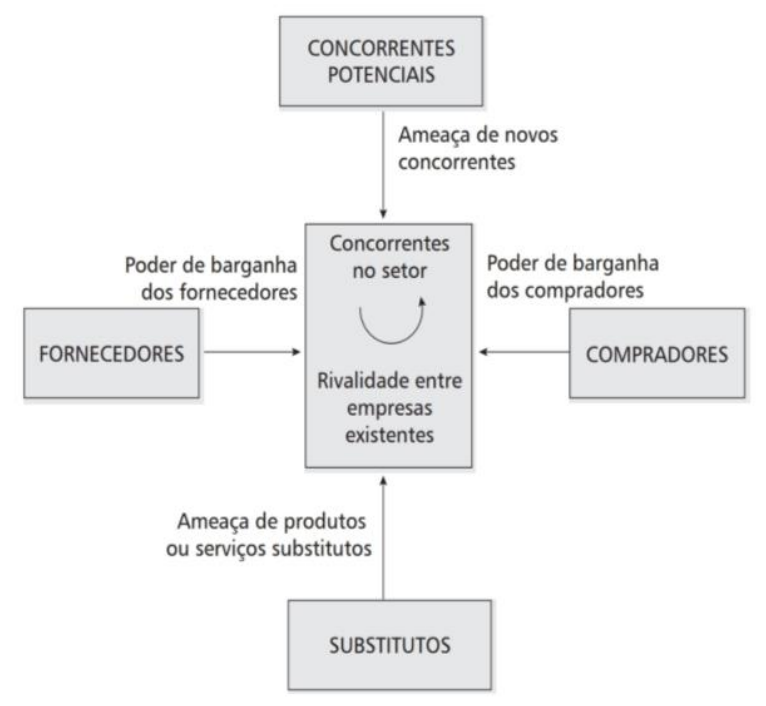

Fonte: Oliveira (2014). 
O modelo das forças de Porter mostrado na figura acima, é uma estrutura que auxilia nas estratégias competitivas alcançadas nas empresas.

\section{Metodologia}

Este trabalho consiste em uma pesquisa de natureza aplicada, baseada em questionários contendo perguntas fechadas e abertas, buscando obter opinião dos empresários acerca da consultoria em Gestão de Pessoas.

Os sujeitos participantes da pesquisa foram empresários da Região do Cariri Cearense que se disponibilizarem a participar voluntariamente do questionário. Estes foram selecionados de acordo com a amostragem por conveniência acreditando que possam representar significativamente o universo e o fenômeno no qual estavam inseridos (GIL, 2009).

A coleta de dados foi realizada mediante o envio do questionário Google forms por meio do link enviado através de contatos eletrônicos, tais como e-mail, whatsaap e também por abordagem pessoal com o questionário impresso.

O questionário (em anexo) continha perguntas de cunho sociodemográfico e perguntas relacionadas a opinião dos empresários sobre Consultoria em Gestão de Pessoas, para Vergara (2012) questionário é a forma de coleta de dados, em um determinado local, onde interage analisando uma determinada questão ou temática.

O presente trabalho possui como método de pesquisa quanti-qualitativa, constituído por perguntas fechadas e abertas que fornecerão dados primários caracterizando a pesquisa como quanti-qualitativa visto que irá explorar dado quantificáveis.

Quanto à análise dos dados classificam-se de acordo com a análise exploratórias. Busca determinado assunto específico que não poderão surgir hipóteses, a não serem no decorrer da pesquisa. Descritivas, pois visou discorrer sobre acontecimentos de um determinado assunto e descrever um fenômeno para tal conclusão (VERGARA, 2016).

Este artigo teve a importância de mostrar o consultor nas organizações e, como ele contribui com a elevação dos resultados na organização, aumentando a produtividade dos seus funcionários, bem como ampliando a atuação a respeito desse profissional de consultoria em gestão de pessoas, além de proporcionar novas habilidades sobre seu papel na organização. 


\section{Análise e Discussão dos Resultados}

Na pesquisa realizada, foi mostrado o percentual de gênero, demostrando que o perfil que mais envolveu na pesquisa foi o público feminino, com cerca de $69 \%$ e $31 \%$ para o com público masculino.

As idades dos participantes da pesquisa obtiveram uma discrepância para os com idade entre 18 e 25 anos, o com mais de 35 anos, representaram $16 \%$ da amostra e entre 26 e 35 anos $22 \%$.

O estado civil destes, foram considerados a seguinte forma: $66 \%$ solteiros (a), $25 \%$ casados (a), $4 \%$ divorciado, $5 \%$ em união estável. Nesta etapa foi pesquisado se os participantes possuem filhos, em análise geral 68\% não possuem filhos e $32 \%$ possuem filhos.

As cidades onde obteve-se um maior número de participantes foi Juazeiro do Norte, representando $70 \%$ da amostra, Barbalha com 15\%, Crato com 10\%, Missão Velha com 2\%, seguindo de Caririaçu e Jardim com $1 \%$.

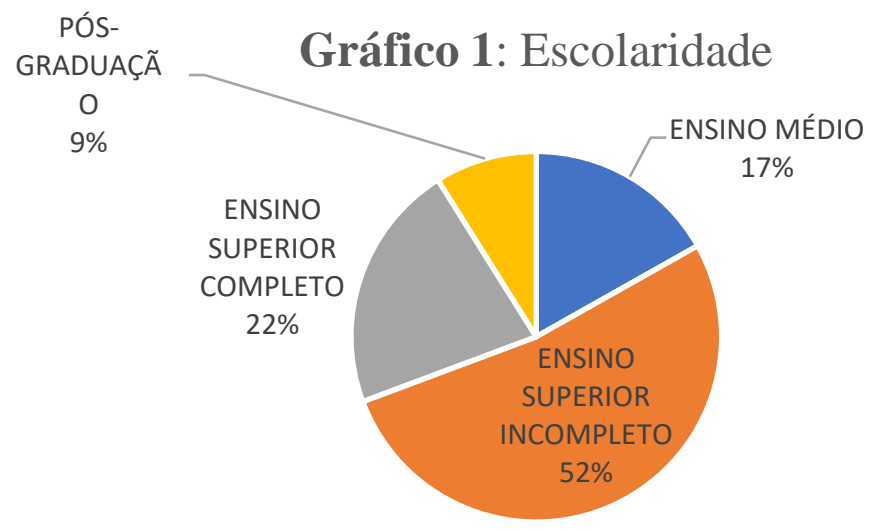

Fonte: Dados da pesquisa (2018).

No gráfico acima, foi perguntado aos seus participantes o nível de escolaridade a maioria com ensino superior incompleto com $52 \%$, com ensino superior completo $22 \%$, e um a pequena quantidade menos significativas com pós-graduação de apenas $9 \%$. 


\section{Grafico 2-RAMO DE ATUAÇÃO}

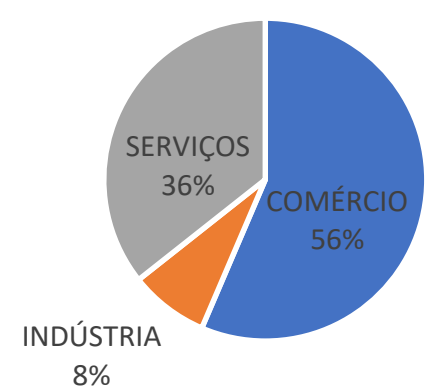

Fonte: Dados da pesquisa (2018)

O gráfico acima mostra o ramo de atuação dos empresários na região do cariri, tendo uma maior representatividade para os ramos na área de Comércio, 52\%, que parte da probabilidade comercial que configura a maioria das empresas dos participantes da região como polo comercial.

\section{Gráfico 3-Tempo de Abertura da Empresa}

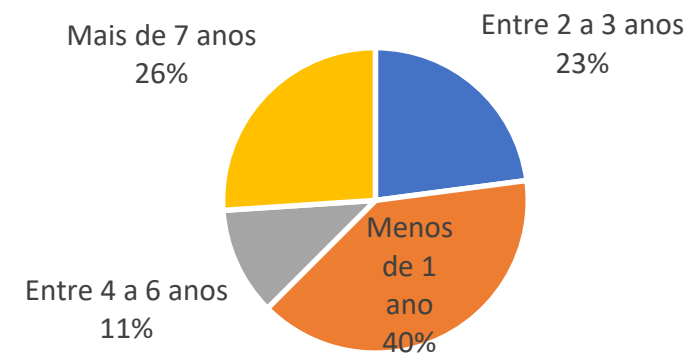

Fonte: Dados da pesquisa (2018)

Nesta etapa percebe-se que a maioria dos participantes possuem empresas a menos de um ano de atuação no mercado de trabalho, o que leva a inferir que são organizações que ainda estão se estruturando e se adaptando as demandas do mercado. 


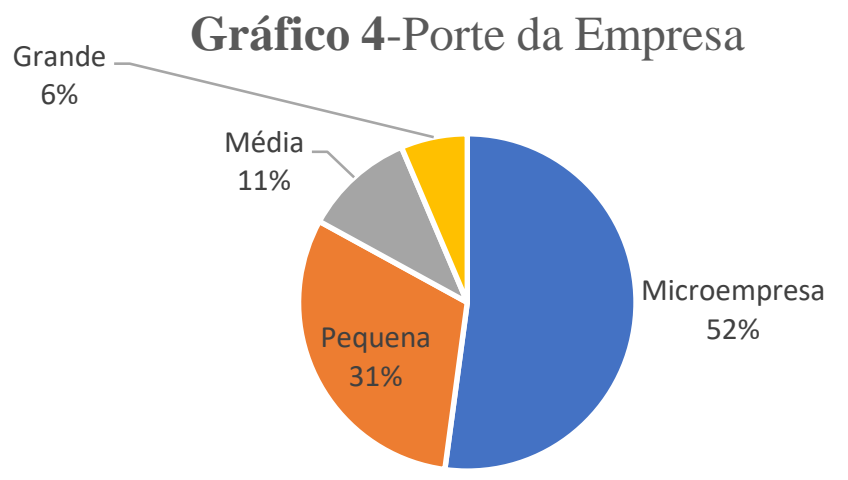

Fonte: Dados da pesquisa (2018)

Neste gráfico menciona-se os seguintes resultados: uma maior discrepância para empresários com microempresa, ou seja, que possui uma receita de 360 mil e empresa de pequeno porte tem um faturamento maior de 361 mil (SEBRAE 2010 apud COSTA, 2015). Isso pode suscitar uma relação entre tempo de atuação da empresa na região e a possibilidade de crescimentos destas, pois a maioria também possui menos de 1 ano de atuação.

\section{GRAFICO 5 -Em qual cidade está localizada a sua empresa?}

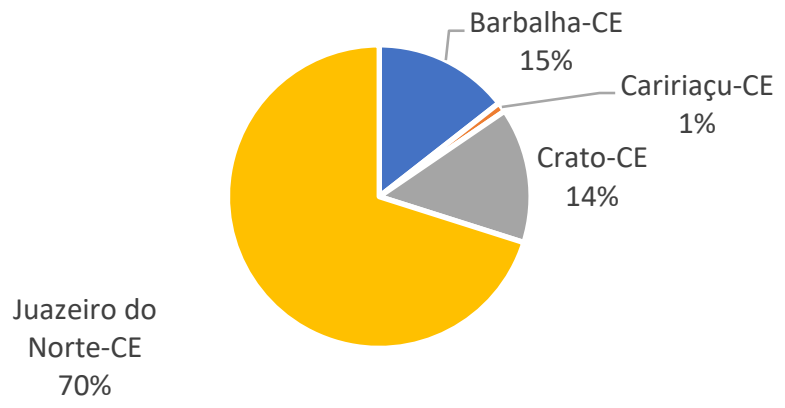

Fonte: Dados da pesquisa (2018)

A localização das empresas dos empresários, em sua maioria com localização está em Juazeiro do Norte-CE, que compreende-se este fator, por ser também o local onde a maioria dos empresários participantes residem, se feito o comparativo entre residência dos mesmos e localização das empresas, apenas Missão Velha e Jardim apresenta um município em que o empresário reside, no entanto, sua empresa não está localizada na cidade. 


\section{Gráfico 7 -Você sabe o que é uma Consultoria em Gestão de Pessoas?}

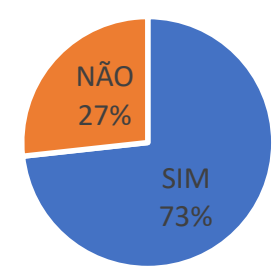

Fonte: Dados da pesquisa (2018)

A maioria sabe o que é uma consultoria em gestão de pessoas e que desta forma percebese que este empresário sabem que a Consultoria em Gestão de Pessoas é uma atividade que ajuda na melhoria da qualidade de vida e de trabalho em um grupo de funcionários de uma empresa, buscando atingir suas metas e prazos no ambiente de trabalho (LEITE et al., 2009).

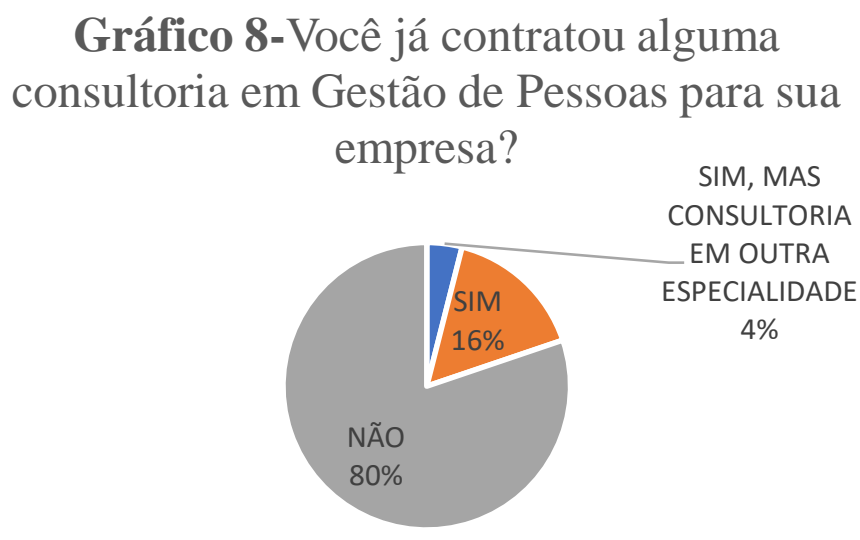

Fonte: Dados da pesquisa (2018)

O gráfico apresenta que a maioria dos empresários não contrataram a consultoria especializada em Gestão de Pessoas, $80 \%$ destes. Ademais, pode-se perceber que de um modo geral as empresas não contratam consultoria em nenhuma outra especialidade, visto que apenas $4 \%$ destes empresários utilizaram algum tipo de consultoria para suas organizações. 


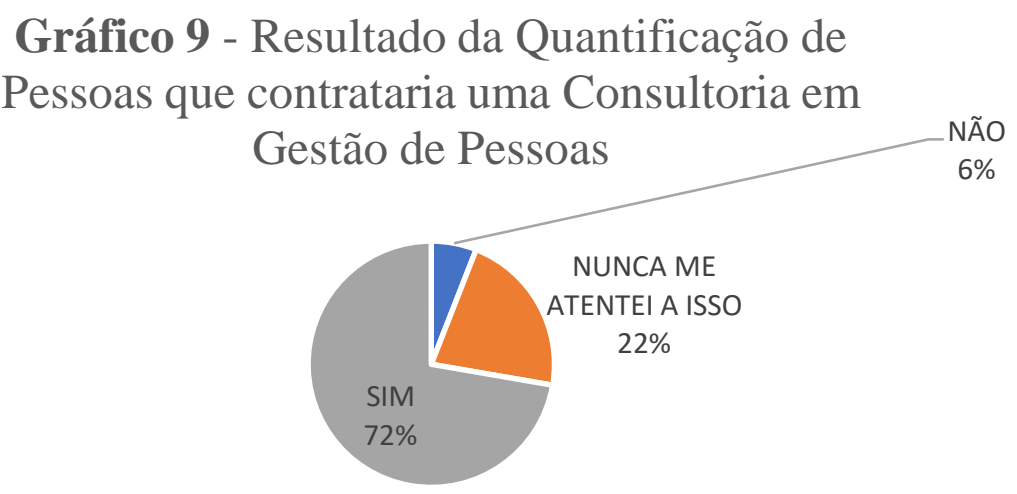

Fonte: Dados da pesquisa (2018)

"A consultoria empresarial é um segmento que mais cresce no mundo" (OLIVEIRA, 2015) Visto isso, a consultoria aumenta a competitividade no mercado, e consegue atingir seus objetivos.

Neste gráfico, apresenta um dado positivo com relação ao interesse dos empresários em possivelmente contratar uma empresa de consultoria especializada em Gestão de Pessoas, o gráfico também revela que $22 \%$ destes não se atentaram a possibilidade de contratação de uma consultoria especializada, o que também se pode inferir que esta não seja uma prioridade para os mesmo neste momento.

\section{Gráfico 10 - Resultado do Principal Objetivo de uma}

Consultoria

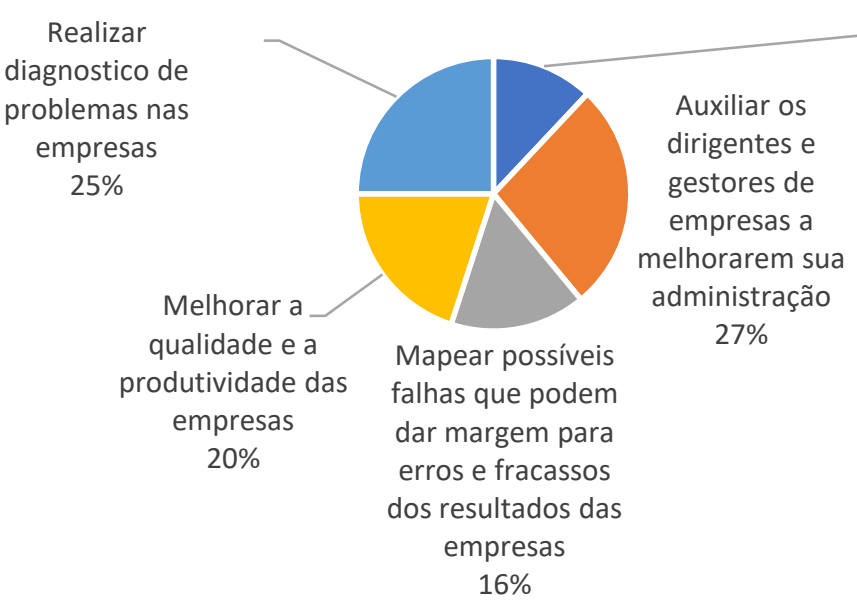

Estabelecer uma administração mais ágil e competitiva nas empresas $12 \%$

Fonte: Dados da pesquisa (2018) 
Neste gráfico, observa-se o nível de conhecimento dos mesmos sobre o que eles acreditam que seria o principal objetivo de uma consultoria. Os dados não apresentam uma relevância significativa de resposta em uma alternativa, tendo uma leve tendência percentual maior no tocante ao objetivo da consultoria em Auxiliar os dirigentes e gestores a melhorarem a administração de suas empresas.

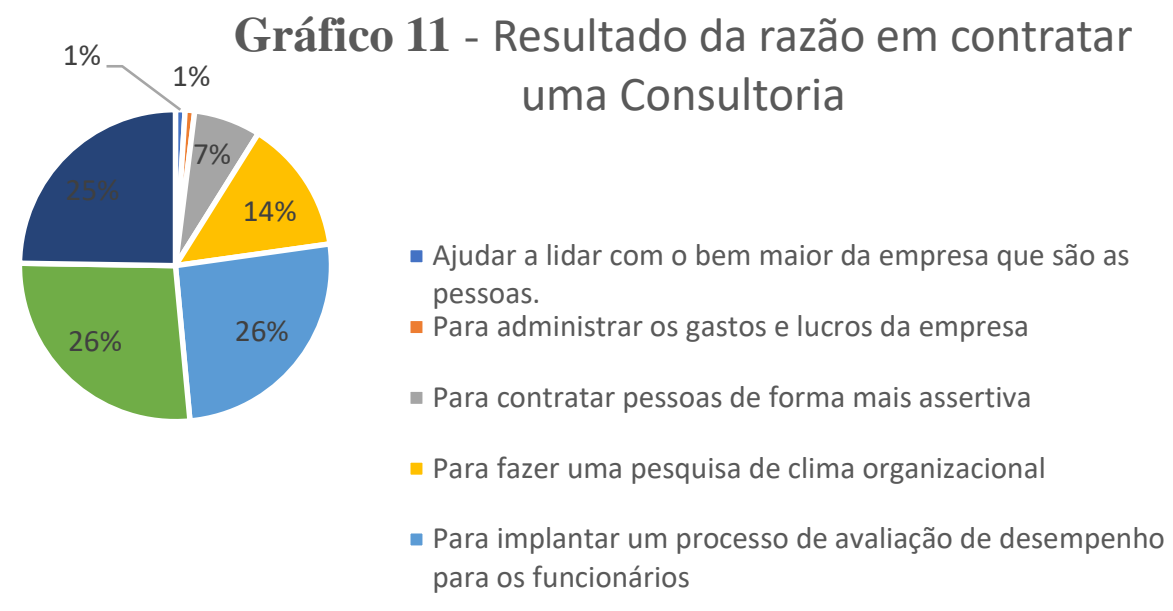

Fonte: Dados da pesquisa (2018)

Ao analisar as respostas dos empresários a respeito da consultoria em Gestão de Pessoas, é necessário observar que as suas respostas podem ter relação com as necessidades de cada empresa e por isso denota-se que as respostas de um modo geral levaram a uma maior predominância a necessidade de reorganizar os cargos e funções, implantar um processo de avaliação de desempenho para os funcionários e treinar os funcionários.

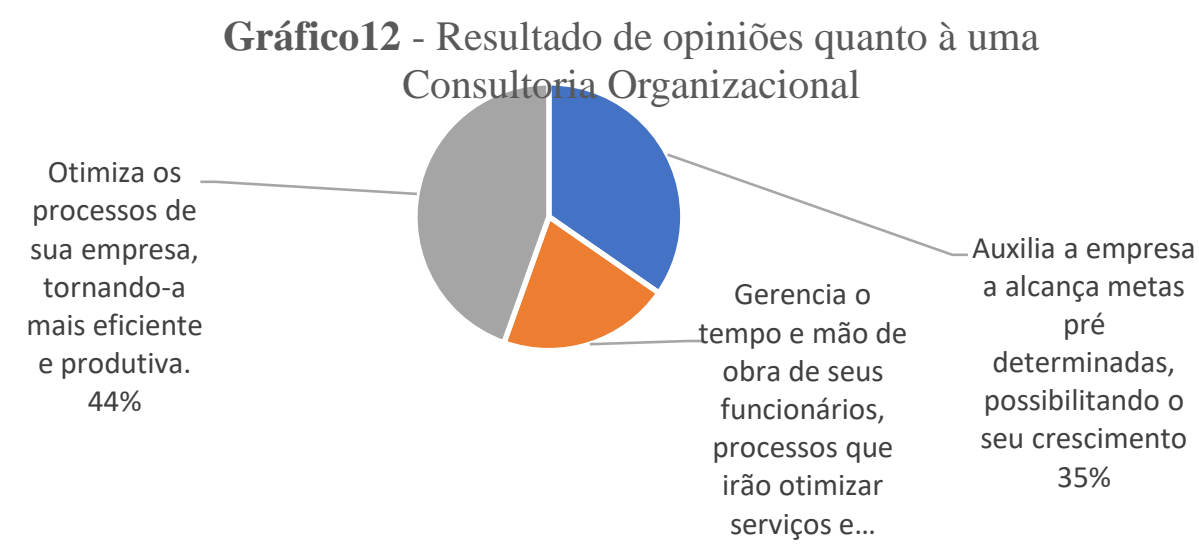

Fonte: Dados da pesquisa (2018) 
Para (MANCIA 1997 apud COSTA 2005) “consultoria organizacional é uma expressão utilizada para definir uma relação de interação". Pois envolve técnicas para soluções de problemas. Porém, a maioria do resultado foi aperfeiçoar os processos de sua empresa, tornando a mais eficiente e produtivas e com percentual menor que a consultoria gerencia o tempo e mão de obra de seus funcionários, processos que irão otimizar serviços e tarefas diárias.

\section{Gráfico 13 - Você conhece algum consultor especializado em Gestão de Pessoas?}

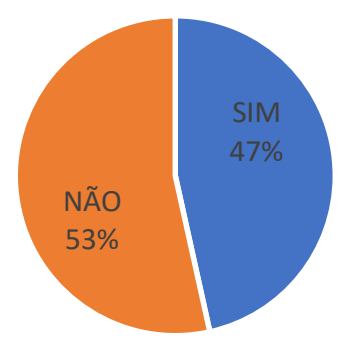

Fonte: Dados da pesquisa (2018)

Este dado apresenta uma resposta significativa e importante para a consultoria em Gestão de Pessoas, visto que 53\% destes profissionais não conhecem nenhum profissional desta área, o que leva a possibilidades de ampliar a divulgação deste para melhorias dos processos organizacionais das empresas da região.

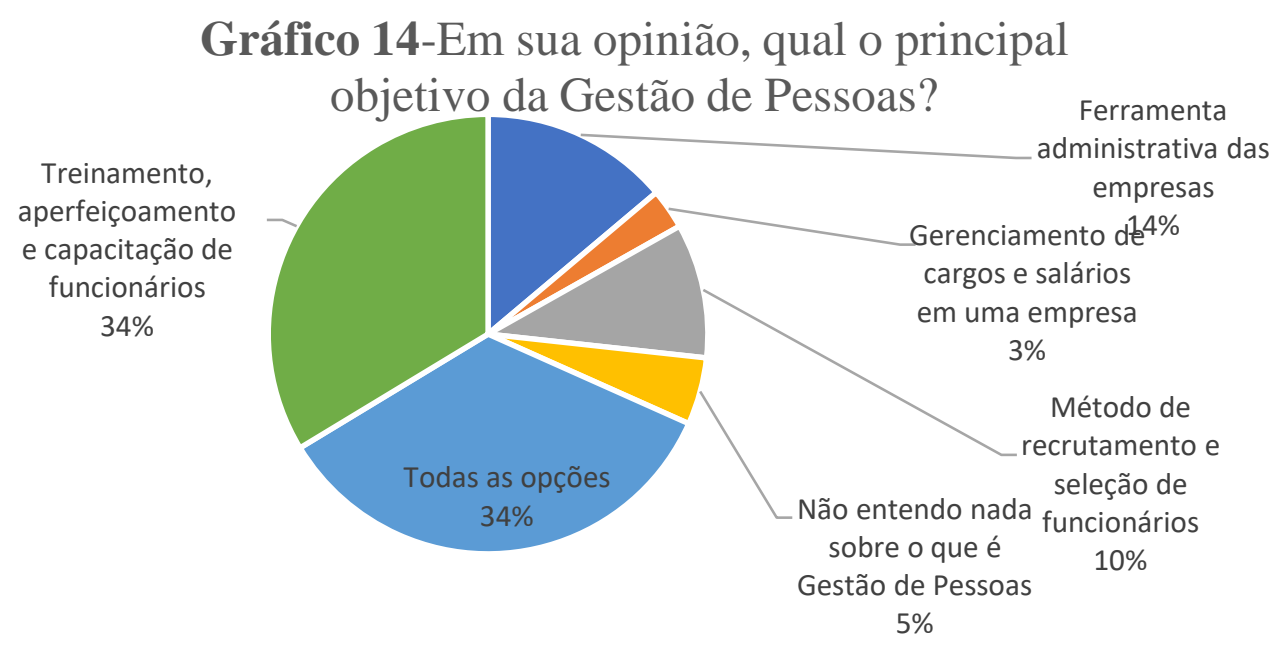

Fonte: Dados da pesquisa (2018) 
Para Chiavenato (2014 p.11) seu principal objetivo na organização é torna se competitivo mantendo de forma consciente e sempre atenta aos seus funcionários.

No gráfico acima, o principal objetivo destacado foi o treinamento, aperfeiçoamento e capacidade de funcionários, e outra metade responderam todas outras alternativas.

\section{Gráfico 15 - Resultado do motivo por não ter contratado uma consultoria}

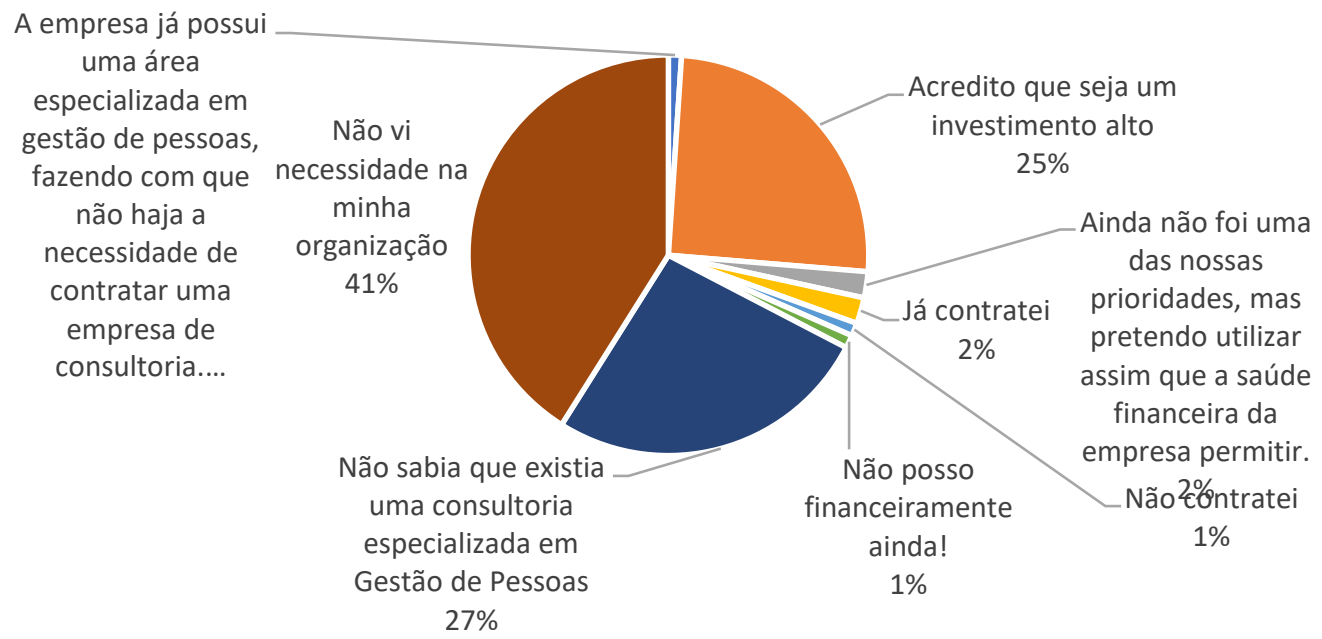

Fonte: Dados da pesquisa (2018)

Neste gráfico, pode-se perceber que apresenta uma confirmação sobre a falta de conhecimentos dos empresários acerca deste profissional em consultoria. Outra resposta relevante é que os empresários não sentem necessidade deste profissional em suas empresas, pois pode-se inferir que por não conhecerem os serviços que o consultor em Gestão de Pessoas pode trazer de benefícios para suas empresas, consequentemente não conseguem visualizar sua necessidade.

\section{Considerações Finais}

A consultoria em gestão de pessoas é uma área bastante desafiadora, pois tem a função de buscar resultados positivos. Visto que o profissional de consultoria atua em uma determinada área em busca de soluções para determinado problema e aconselhamentos. 
Na Região do Cariri é possível perceber que os empresários em sua maioria possuem microempresas e por terem um corpo de funcionários menor, não investem nos desenvolvimentos dos funcionários, sobretudo, na qualificação dos mesmos, outrossim, a maioria das empresas dos empresários participantes possuem uma atuação a menos de 1 ano e por isso, ainda estão em processo de adaptação e ficção no mercado de trabalho local.

Pode-se também observar que os empresários não conhecem o trabalho de uma consultoria especializada em Gestão de Pessoas, por isso, não visualizam necessidade em suas empresas ou não priorizaram este serviço no momento, sobretudo, alguns apresentaram que pode ser um investimento alto e por isso não contrataram este profissional.

Assim, esta pesquisa revela dados significativos para os profissionais consultores da Região do Cariri, com potencial para desenvolver alternativas de divulgar melhor os serviços que podem ser feitos por eles, Sobretudo, apresenta uma possibilidade de investimento de futuros profissionais na região que queiram investir em consultoria nesta área, visto a demanda e necessidade de desenvolvimento principalmente nas empresas que ainda estão iniciando no mercado.

Ademais, os empresários ao participar desta pesquisa puderam despertar uma atenção a possibilidade de uma consultoria em Gestão de Pessoas, visto que seria importante que os empresários da Região do Cariri pudessem analisar esse ramo que pode alavancar a competitividade de sua empresa e aumentar lucros nas suas organizações.

\section{Referências}

ALVES, Giovanni; SANTOS, João Bosco Feitosa dos(org). Métodos e técnicas de pesquisa sobre o mundo do trabalho. Bauro: canal 6, 2014

BETHLEM, Agrícola de Souza. Estratégias empresarial: conceitos, processos e administração de estratégias. 4 ed. São Paulo: Atlas, 2002.

CHIAVENATO, Idalberto. Planejamento estratégico. Arão Sapiro.-Rio de Janeiro: Elsevier, 2003- $4^{\circ}$ reimpressão

CHIAVENATO, Idalberto. Gestão de Pessoas: O novo papel dos recursos humanos nas organizações. 4. ed. Califórnia: Manole Ltda, 2014. 11 p. 
COSTA, Narjara de Oliveira. Consultoria em Gestão de Pessoas: Uma Análise das Oportunidades e Desafios Encontrados na Prática. 2015. Disponível em: <http://bibliodigital.unijui.edu.br:8080/xmlui/bitstream/handle/123456789/2587/Publicação Artigo MBA Gestão de Pessoas_Narjara Costa.pdf?sequence=1>. Acesso em: 06 maio 2018.

FIDELIS, Gilson José. Gestão de pessoas: Estrutura, Processos e estratégias empresarias. 1.ed. São Paulo: Érica.

GIL, Antônio Carlos. Metodo e técnicas de Pesquisa Social. 6 ed. São Pulo: Atlas,2009.

LEITE, Luiz Augusto Mattana da Costa et al. Consultoria em Gestão de Pessoas. 2. ed. Rio de Janeiro: Fgv, 2009. 27 p.

LEITE, Luiz Augusto Mattana da Costa et al. Consultoria em Gestão de Pessoas. 2. ed. Rio de Janeiro: Fgv, 2009. 27 p

MATIAS-PEREIRA, Jose. Manual de Metodologia da Pesquisa Cientifica. $4^{\mathrm{a} e d}$.São Paulo. Atlas, 2016.

MINAYO, M.C.S. Pesquisa Social. 32a ed. Petropólis,RJ ;Vozes,2012.

OLIVEIRA, Djalma de Pinho Rebouças de. Manual de Consultoria Empresarial: conceitosmetodologia-praticas. 13. ed. São Paulo: Atlas, 2003. 21 p.

VERGARA, Sylvia Constant. Projetos e Relatório de Pesquisa em Administração. $16^{\text {a }}$ ed. São Paulo: Atlas,2016.

WEIS, Alan. Consultor ouro: guia profissional para construção de uma carreira $4^{\mathrm{a}}$ edição, 2012.

\section{Como citar este artigo (Formato ABNT):}

CARVALHO, Márcia Marta de; RODRIGUES, Larissa Vasconcelos. A Percepção dos Empresários Sobre a Consultoria em Gestão de Pessoas na Região do Cariri. Id on Line Rev.Mult. Psic., 2018, vol.12, n.42, Supl. 1, p. 427-446. ISSN: 1981-1179.

Recebido: 07/11/2018;

Aceito: 08/11/2018 